\title{
ÁGUAS SUBTERRÂNEAS EM RONDÔNIA: ANÁLISE ESTATÍSTICA DE DADOS HIDROQUÍMICOS, ORGANOLÉPTICOS E BACTERIOLÓGICOS
}

\author{
Catia Eliza ZUFFO \\ Francisco de Assis Matos de ABREU \\ Itabaraci Nazareno CAVALCANTE \\ Gerson Flôres NASCIMENTO
}

\begin{abstract}
RESUMO
Com vistas a contribuir e aprimorar o processo de gestão em andamento das águas subterrâneas do Estado de Rondônia, os dados de 384 resultados de análises físico-químicas e/ou bacteriológicas de poços constantes nos arquivos do $2^{\circ}$ Zoneamento Sócio-Econômico-Ecológico do Estado de Rondônia - ZSEE/RO, apresentados por localidades, foram tratados e reorganizados por bacia hidrográfica. Buscou-se a caracterização da qualidade de águas subterrâneas nas principais bacias hidrográficas do Estado de Rondônia, considerando propriedades físicas (cor, pH e turbidez), químicas (cloreto, ferro total, sulfato, oxigênio consumido, dureza total, dureza em cálcio, dureza em magnésio, sólidos totais, nitrogênio nitrito, nitrogênio nitrato, gás carbônico livre e alcalinidade $\mathrm{HCO}_{3}$ ) e bacteriológicas (contagem padrão de bactérias, número mais provável de coliformes totais, número mais provável de coliformes fecais e número mais provável de colônias - método membrana filtrante). Para testar o ajuste dos dados à distribuição normal foi utilizado o método de Kolmogorov-Smirnov, modificado por Lilliefors. O estudo demonstrou que as águas subterrâneas analisadas possuem boa qualidade físico-organoléptica. As bacias dos rios Madeira e Machado apresentam maiores alterações nos valores de $\mathrm{pH}$, cloreto e nitrato, caracterizando perda de qualidade dos recursos hídricos subterrâneos, em função do adensamento populacional. A bacia hidrográfica do rio Abunã caracteriza-se como a de maior risco de contaminação fecal. Em geral, as águas analisadas apresentam resultados que excedem os padrões bacteriológicos de potabilidade, necessitando de tratamento por cloração ou fervura e prévia filtração para consumo humano.
\end{abstract}

Palavras-chave: qualidade das águas, águas subterrâneas, Rondônia.

\section{ABSTRACT}

In order to improve the ongoing process of managing groundwaters in the State of Rondonia we collected the results of 384 physical-chemical and / or bacteriological analyses of wells on file in the 2nd Socio-Economic and Ecological Zonation of the State of Rondonia, Brazil - ZSEE / RO, submitted by localities. We then treated and reorganized these data according to hydrographic basins using spreadsheets. We sought to characterize the quality of groundwater in major watersheds of the state of Rondonia by considering physical (color, $\mathrm{pH}$ and turbidity), chemical (chloride, total iron, sulfate, oxygen consumption, total hardness, calcium hardness, magnesium hardness, total solids, nitrogen as nitrite, nitrogen as nitrate, free carbon dioxide and $\mathrm{HCO}_{3}$ alkalinity) and bacteriological (standard bacterial counts of most probable number of coliform bacteria, most probable number of fecal coliform bacterial, most probable number of colonies - membrane filter method) properties. In order to test the adjustment of the data obtained to a normal distribution, we used the Kolmogorov-Smirnov method, modified by Lilliefors. The study revealed that the groundwater analyzed had good physical-organoleptic properties; the basins of the Madeira and of the Machado rivers 
showed the greatest changes in $\mathrm{pH}$ values, chloride and nitrate, indicative of a loss of quality of groundwater resources depending on population density. The Abunan river basin revealed the highest risk of fecal contamination, with water samples generally showing results that exceeded the bacteriological standards, thus requiring treatment by chlorination or boiling and filtration before human consumption.

Keywords: water quality, groundwater, Rondonia.

\section{INTRODUÇÃO}

O Brasil é um país com diversidade em vários aspectos, como o ambiental, privilegiado em termos de disponibilidade hídrica total, com aproximadamente $12 \%$ das reservas mundiais de água doce. Em estudos mais detalhados, no entanto, observam-se situações extremas que variam da abundância à escassez de água. Outro aspecto diz respeito à qualidade da água, o que torna imprescindível, cada vez mais, o envolvimento da sociedade civil, dos usuários e do governo no planejamento e na gestão dos recursos hídricos (BRASIL 2005a).

Em Decreto de 22 de março de 2005, o Presidente da República instituiu a Década Brasileira da Água, de 2005 a 2015, estimulando a sociedade à compreensão da importância da água como elemento essencial para a vida e para o desenvolvimento.

A água, portanto, é um bem comum que deve ser administrado de modo a garantir seu uso múltiplo e a sustentabilidade das várias formas de vida, maximizando o bem-estar social.

Nessa perspectiva, foi instituída a Política Nacional de Recursos Hídricos, a partir da Lei $\mathrm{n}^{\circ}$. 9.433, de 08/01/1997, que criou o Sistema Nacional de Gerenciamento de Recursos Hídricos, regulamentando o Inciso XIX do Art. 21 da Constituição Federal e dando outras providências, constituindo "uma Lei de Organização Administrativa" para este setor (BRASIL 1997).

Em meados da década de 1990, o consumo total per capita, em países relativamente mais desenvolvidos do que o Brasil, situava-se aproximadamente entre 500 a $1.000 \mathrm{~m}^{3} /$ ano (REBOUÇAS 1997). Nesse período, alguns estados brasileiros tinham disponibilidade de água similar a de alguns países, por exemplo: Pernambuco $1.320 \mathrm{~m}^{3} / \mathrm{hab} /$ ano, Alemanha $1.160 \mathrm{~m}^{3} / \mathrm{hab} / \mathrm{ano}$; Bahia $3.028 \mathrm{~m}^{3} /$ hab/ano, França $3.030 \mathrm{~m}^{3} /$ hab/ano; Piauí $9.608 \mathrm{~m}^{3} /$ hab/ano, Estados Unidos $9.940 \mathrm{~m}^{3} / \mathrm{hab} /$ ano (REBOUÇAS 1997). Mesmo com essas taxas de disponibilidade per capita/ano de água, os estados do nordeste do Brasil sempre apresentaram, no con- junto, um quadro de escassez de água, caracterizando, assim, a necessidade de melhor gerenciar os recursos hídricos disponíveis.

A gestão de recursos hídricos subterrâneos a partir da implantação de comitês de bacias tem se mostrado uma ferramenta cada vez mais eficiente (BARBOSA \& MATTOS 2006), principalmente quando se refere a riscos de poluição dessas águas, associados aos lixões e despejos industriais nocivos (FOSTER 1993).

O Estado de Rondônia, localizado na porção sudoeste da Amazônia Legal Brasileira, compreende 52 municípios. Apresenta características peculiares, tais como: ser uma área de transição entre os domínios morfoclimáticos amazônico e do cerrado, com várias subdivisões geomorfológicas, e ter um clima quente, com período mais chuvoso de outubro a abril, refletido principalmente na vegetação, drenagem superficial e recarga dos aquíferos.

A Secretaria de Estado do Desenvolvimento Ambiental - SEDAM (2002), embasada nos estudos de SCANDOLARA et al (1999), afirma que, em relação ao quadro geológico, o Estado de Rondônia está localizado "a oeste da região conhecida como Província Tapajós, também recebendo a denominação de Subprovíncia Madeira, segundo a proposta de AMARAL (1984)"'. Sinteticamente, destaca-se a presença de rochas do embasamento (Proterozóico Inferior e Médio), ocorrendo, também, granitos intrusivos (Proterozóico Médio e Superior). As coberturas vulcânica e sedimentar compreendem rochas do Proterozóico Médio ao Superior, Paleozóico, Mesozóico; destacam-se as coberturas cenozóicas, no Baixo Rio Machado, e ao longo dos vales dos rios Guaporé, Mamoré e Madeira.

A lei que institui a política rondoniense de recursos hídricos (RONDÔNIA 2002a), que tem por objetivos básicos promover o uso racional, múltiplo e o gerenciamento integrado das águas de domínio do estado, superficiais e subterrâneas, em seu artigo $3^{\circ}$, define as seguintes diretrizes:

I - descentralizar a gestão das águas, mediante o gerenciamento por bacia hidrográfica, sem dissociação dos aspectos quantitativos e qualitativos 
e das fases meteórica, superficial e subterrânea do ciclo hidrológico, assegurada a participação do poder público, dos usuários e da comunidade; (...).

Não existem muitos trabalhos científicos referentes à ocorrência das águas subterrâneas no Estado de Rondônia. Dos trabalhos existentes, alguns são relatórios técnicos do Serviço Geológico do Brasil - Residência de Porto Velho (antes denominada de Companhia de Pesquisa de Recursos Minerais - CPRM). Outros são artigos, monografias, dissertações ou teses, e desses, a maioria concentra-se nas áreas dos dois maiores municípios do estado, Ji-Paraná e Porto Velho, a capital.
Nos quadros 1 a 4, apresentados a seguir, é mostrada a síntese desses trabalhos, destacando os aspectos relacionados à qualidade das águas subterrâneas rondonienses. O estudo mais abrangente no contexto estadual, abordando a qualidade das águas subterrâneas de Rondônia, foi o relatório técnico de hidrogeologia do $2^{\circ}$ Zoneamento Sócio-Econômico-Ecológico - $2^{\circ}$ ZSEE (RONDÔNIA 1998), cujos dados foram disponibilizados por cidade/distrito. O presente estudo buscou reorganizar esses dados por bacia hidrográfica, visando subsidiar o processo em andamento de gestão das águas subterrâneas de Rondônia.

QUADRO 1 - Informações sobre a qualidade das águas subterrâneas na bacia hidrográfica do rio Abunã.

\begin{tabular}{|l|l|l|}
\hline \multicolumn{1}{|c|}{ Autoria } & \multicolumn{1}{|c|}{ Área Analisada } & \multicolumn{1}{c|}{ Resultado(s) } \\
\hline $\begin{array}{l}\text { CAMPOS et al. } \\
\text { (1999a) }\end{array}$ & $\begin{array}{l}\text { Área urbana de Nova } \\
\text { Califórnia - distrito de } \\
\text { Porto Velho }\end{array}$ & $\begin{array}{l}\text { Cacimbas contaminadas pelas fossas domésticas e outras } \\
\text { fontes poluentes, necessitando de cloração ou fervura da } \\
\text { água captada para adequar ao consumo humano. }\end{array}$ \\
\hline $\begin{array}{l}\text { CAMPOS \& DREWS } \\
(1999)\end{array}$ & $\begin{array}{l}\text { Área urbana de } \\
\text { Extrema - distrito de } \\
\text { Porto Velho }\end{array}$ & $\begin{array}{l}\text { Cacimbas contaminadas pelas fossas domésticas e outras } \\
\text { fontes poluentes, necessitando de cloração ou fervura da } \\
\text { água captada para adequar ao consumo humano. }\end{array}$ \\
\hline
\end{tabular}

QUADRO 2 - Informações sobre a qualidade das águas subterrâneas na bacia hidrográfica do rio Madeira.

\begin{tabular}{|c|c|c|}
\hline Autoria & Área Analisada & Resultado(s) \\
\hline BAHIA (1997) & Zona urbana de Porto Velho & $\begin{array}{l}\text { - Nitrato e bactérias do grupo coliforme na maioria das } \\
\text { amostras de águas subterrâneas; } \\
\text { - Há águas subterrâneas pobres em eletrólitos e outras } \\
\text { mais ricas. }\end{array}$ \\
\hline $\begin{array}{l}\text { CAMPOS et al. } \\
(2004)\end{array}$ & $\begin{array}{l}\text { Bairros São João Bosco e } \\
\text { Liberdade - Porto Velho }\end{array}$ & $\begin{array}{l}70 \% \text { das amostras de nitrato estão com valores acima } \\
\text { de } 3 \mathrm{mgN} / \mathrm{L} \text { - indicativo de efeito antrópico. }\end{array}$ \\
\hline $\begin{array}{l}\text { MELO JR. \& } \\
\text { COSTI (2004) }\end{array}$ & Bairro Vila Tupi - Porto Velho & $\begin{array}{l}\text { Nas amostras de água coletadas em poços, foram } \\
\text { identificados valores entre } 53 \text { a } 193 \mathrm{mg} / \mathrm{L} \text { de óleos e } \\
\text { graxas e } 14 \text { a } 95 \mathrm{mg} / \mathrm{L} \text { de hidrocarbonetos. }\end{array}$ \\
\hline $\begin{array}{l}\text { MELO JR. et al. } \\
(2006)\end{array}$ & $\begin{array}{l}\text { Bairro Eletronorte - Porto } \\
\text { Velho }\end{array}$ & $\begin{array}{l}80 \% \text { das amostras apresentam indicativo de alteração } \\
\text { antrópica na qualidade das águas subterrâneas. }\end{array}$ \\
\hline $\begin{array}{l}\text { MELO JR. } \\
(2007)\end{array}$ & Área urbana de Porto Velho & $\begin{array}{l}\text { Estudos demonstram alterações na qualidade das águas } \\
\text { do aquífero Jaciparaná - principal fornecedor de água } \\
\text { subterrânea para a população da capital rondoniense. }\end{array}$ \\
\hline LIMA (2008) & Zona sul de Porto Velho & $\begin{array}{l}\text { Várias amostras de águas subterrâneas apresentaram } \\
\text { teores de nitrato acima do limite máximo permitido no } \\
\text { Brasil que é de } 10 \mathrm{mg} / \mathrm{L} \text {. }\end{array}$ \\
\hline $\begin{array}{l}\text { LIMA et al. } \\
\text { (2008) }\end{array}$ & Zona sul de Porto Velho & $\begin{array}{l}\text { Águas subterrâneas do aquífero livre estão } \\
\text { parcialmente contaminadas com teores de nitrato. }\end{array}$ \\
\hline $\begin{array}{l}\text { RODRIGUES } \\
(2008)\end{array}$ & Área urbana de Porto Velho & $\begin{array}{l}\text { As águas do lençol freático, captadas por meio de } \\
\text { poços amazonas encontram-se com altos índices de } \\
\text { contaminação bacteriológica. }\end{array}$ \\
\hline COSTA (2008) & Área da Lixeira de Porto Velho & $\begin{array}{l}\text { Os poços apresentam alterações significativas nas } \\
\text { análises físico-químicas e bacteriológicas. }\end{array}$ \\
\hline SOUZA (2008) & Área urbana de Porto Velho & $\begin{array}{l}\text { Águas subterrâneas com valores de } \mathrm{pH} \text { abaixo do } \\
\text { recomendado para consumo humano. }\end{array}$ \\
\hline
\end{tabular}


QUADRO 3 - Informações sobre a qualidade das águas subterrâneas na bacia hidrográfica do rio Jamari.

\begin{tabular}{|l|l|l|}
\hline \multicolumn{1}{|c|}{ Autoria } & \multicolumn{1}{|c|}{ Área Analisada } & \multicolumn{1}{c|}{ Resultado(s) } \\
\hline $\begin{array}{l}\text { CAMPOS } \text { et al. } \\
(1999 b)\end{array}$ & Área urbana de Buritis & $\begin{array}{l}\text { Ocorrência de contaminação nas águas } \\
\text { subterrâneas. Presença de coliformes totais. }\end{array}$ \\
\hline $\begin{array}{l}\text { CAMPOS } \text { et al. } \\
(1999 \mathrm{c})\end{array}$ & $\begin{array}{l}\text { Área urbana de Campo } \\
\text { Novo de Rondônia }\end{array}$ & $\begin{array}{l}\text { Cacimbas contaminadas pelas fossas domésticas e } \\
\text { outras fontes poluentes, necessitando de cloração ou } \\
\text { fervura da água captada para consumo humano. }\end{array}$ \\
\hline $\begin{array}{l}\text { CAMPOS \& REIS } \\
(2002)\end{array}$ & $\begin{array}{l}\text { Área urbana de } \\
\text { Ariquemes }\end{array}$ & $\begin{array}{l}\text { Valores de nitrato próximos do limite máximo } \\
\text { permitido para consumo humano de águas } \\
\text { subterrâneas. }\end{array}$ \\
\hline
\end{tabular}

QUADRO 4 - Informações sobre a qualidade das águas subterrâneas na bacia hidrográfica do rio Machado.

\begin{tabular}{|l|l|l|}
\hline \multicolumn{1}{|c|}{ Autoria } & \multicolumn{1}{|c|}{ Área Analisada } & \multicolumn{1}{c|}{ Resultado(s) } \\
\hline REIS et al. (1998) & $\begin{array}{l}\text { Área urbana de Pimenta } \\
\text { Bueno }\end{array}$ & $\begin{array}{l}\text { Águas subterrâneas com elevado teor de sais, } \\
\text { imprópria para o consumo humano, animal e para } \\
\text { irrigação. }\end{array}$ \\
\hline SILVA (2001) & $\begin{array}{l}\text { Bairro Nova Brasília em } \\
\text { Ji-Paraná }\end{array}$ & $\begin{array}{l}\text { Índices extremamente elevados de coliformes e } \\
\text { nitrato foram detectados, tanto no período das } \\
\text { chuvas quanto na estiagem, na maioria dos poços. }\end{array}$ \\
\hline CAMPOS (2004) & $\begin{array}{l}\text { Área urbana de Mirante } \\
\text { da Serra }\end{array}$ & $\begin{array}{l}\text { Evidências de contaminação por cloretos, nitratos e } \\
\text { parâmetros bacteriológicos. }\end{array}$ \\
\hline SILVA (2008) & $\begin{array}{l}\text { Bairro Nova Brasília em } \\
\text { Ji-Paraná }\end{array}$ & $\begin{array}{l}\text { Ecossistema de forte vulnerabilidade frente aos } \\
\text { processos de contaminação. }\end{array}$ \\
\hline
\end{tabular}

No Decreto $n^{\circ} .10 .114$, de 20 de setembro de 2002 (RONDÔNIA 2002b), que regulamenta a Lei Complementar $n^{\circ} .255$, de 25 de janeiro de 2002 , são reafirmados os princípios básicos, objetivos e diretrizes da Política Estadual de Recursos Hídricos de Rondônia, bem como os instrumentos de gestão. Nesse decreto é definido como órgão gestor estadual a SEDAM, e também é estabelecida a divisão hidrográfica do Estado de Rondônia. Das sete bacias hidrográficas em que o Estado está dividido - rio Mamoré $\left(22.790,6631 \mathrm{~km}^{2}\right)$, rio Abunã $\left(4.792,2501 \mathrm{~km}^{2}\right)$, rio Madeira $(31.422,1525$ $\mathrm{km}^{2}$ ), rio Jamari $\left(29.102,7078 \mathrm{~km}^{2}\right)$, rio Machado $\left(80.630,5663 \mathrm{~km}^{2}\right)$, rio Roosevelt $(15.638,1922$ $\left.\mathrm{km}^{2}\right)$ e rio Guaporé $\left(59.339,3805 \mathrm{~km}^{2}\right)$-, apenas as bacias dos rios Guaporé e Roosevelt não foram incluídas neste trabalho, por falta de amostragem (Figura 1).

\section{MATERIAIS E MÉTODOS}

$\mathrm{Na}$ coleta e preservação das amostras de águas subterrâneas procedeu-se da seguinte forma: as amostras foram divididas em partes iguais e preservadas, conforme o parâmetro a se deter- minar $(300 \mathrm{ml}$, coletados em frasco de polietileno esterilizado, acondicionados em gelo, para análises bacteriológicas e $3000 \mathrm{ml}$ para as demais determinações) (RONDÔNIA 1998).

As coletas foram realizadas de janeiro/1995 a dezembro/1997 em poços escavados e tubulares. No entanto, os dados existentes não permitem realizar um estudo evolutivo da composição química d'água subterrânea ao longo do tempo, porque não se dispõe de resultados analíticos em datas distintas para um mesmo poço.

Como não foram identificadas as profundidades dos poços amostrados e dos aquíferos explotados, não foi possível estabelecer relações entre a composição química das águas e a geologia. A profundidade média dos poços escavados (poços Amazonas) foi inferior a 20 metros.

Para a caracterização da qualidade de águas subterrâneas em cinco das principais bacias hidrográficas do Estado de Rondônia, foram consideradas propriedades físicas (cor, pH e turbidez), bacteriológicas (contagem padrão de bactérias, número mais provável de coliformes totais, número mais provável de coliformes fecais e número mais provável de colônias - método membrana filtrante) e químicas 


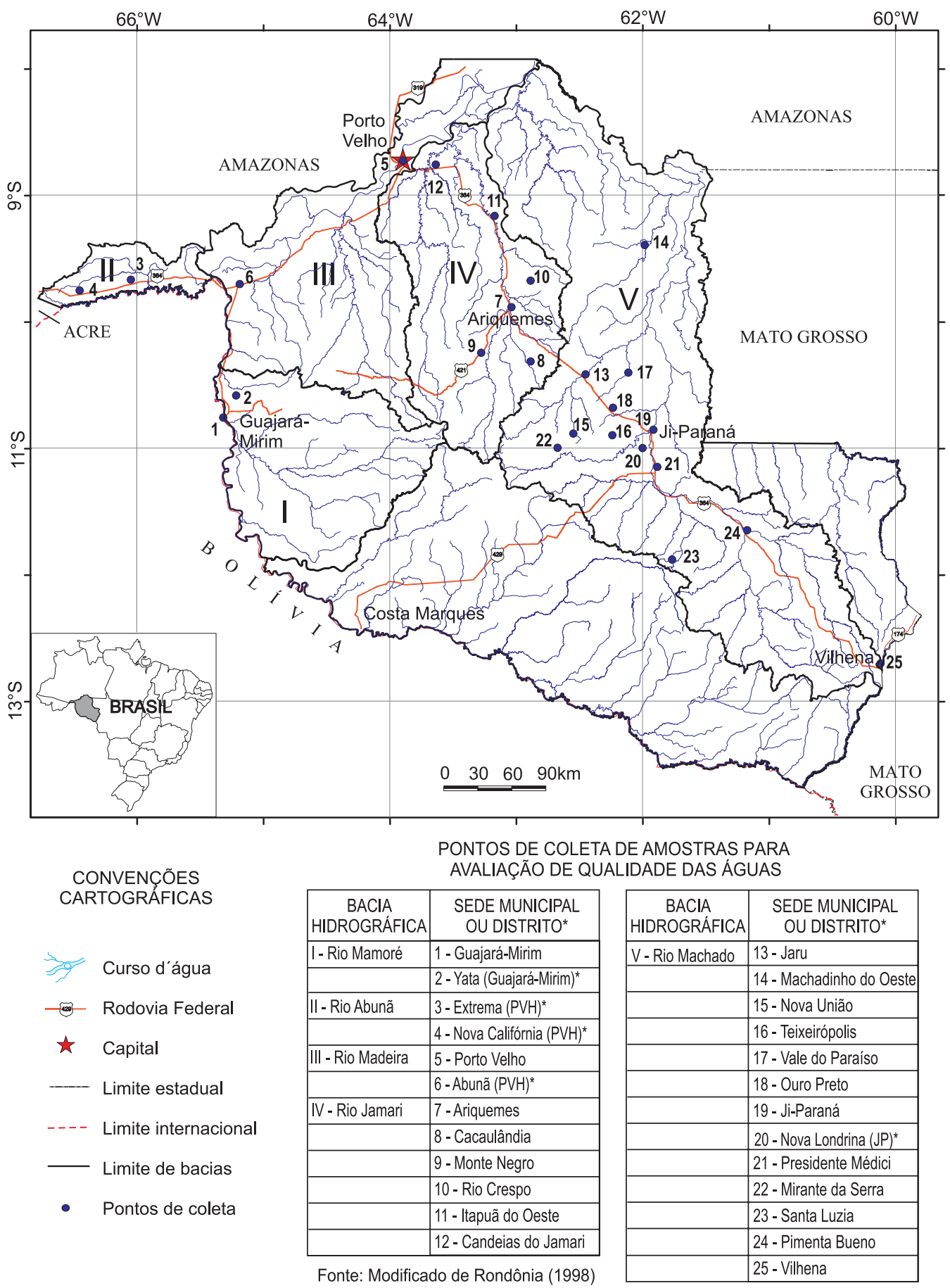

FIGURA 1 - Localização dos pontos de amostragem das águas subterrâneas no estado de Rondônia, conforme RONDÔNIA (1998).

(cloreto, ferro total, sulfato, oxigênio consumido, dureza total, dureza em cálcio, dureza em magnésio, sólidos totais, nitrogênio nitrito, nitrogênio nitrato, gás carbônico livre e alcalinidade $\mathrm{HCO}_{3}$ ). Após coleta e análise laboratorial das amostras, os dados foram organizados em planilha eletrônica, com a utilização do software Statistica, e foram obtidas informações sobre valores de mínimo, máximo, média, moda, desvio padrão e coeficiente de variação (FONSECA 1985, GOMES 1990). 
Para testar o ajuste dos dados à distribuição normal com $5 \%$ de significância - ou seja, se a experiência fosse repetida 100 vezes, admitiu-se que a diferença observada poderia ser falsa em cada 5 ocasiões - foi utilizado o teste de Kolmogorov-Smirnov com a modificação de Lilliefors (LILLIEFORS 1967). A grande maioria das estatísticas foi construída sob a hipótese de normalidade, razão pela qual é indispensável a aplicação de um teste para verificar a normalidade de um conjunto de dados (THODE JR 2002).

\section{RESULTADOS E DISCUSSÕES}

A tabela 1 mostra a distribuição das 225 amostras coletadas para as análises físicas realizadas nas bacias estudadas.
As análises químicas foram realizadas para 207 amostras distribuídas nas bacias estudadas (Tabela 2), enquanto que as determinações bacteriológicas, para um total de 353 amostras (Tabela 3).

Após a obtenção dos resultados analíticos das amostras de água, foi realizada análise numérica simples e obtidos os valores mínimo, máximo e médio e o coeficiente de variação dos parâmetros analisados. Para testar o ajuste dos dados à distribuição normal, foi utilizado o método de Kolmogorov-Smirnov modificado por Lilliefors (LILLIEFORS 1967).

De um modo geral, observa-se que a maioria das amostras de água analisadas apresenta temperatura relacionada com as temperaturas médias do ambiente no momento da coleta, oscilando entre $24^{\circ} \mathrm{C}$ e $30^{\circ} \mathrm{C}$.

TABELA 1 - Distribuição de pontos de amostragem com determinações físicas.

\begin{tabular}{llc}
\hline \multicolumn{1}{c}{ Bacia } & \multicolumn{1}{c}{ Localização dos pontos de amostragem e número de amostras } & $\begin{array}{c}\text { Total de amostras em } \\
\text { cada bacia }\end{array}$ \\
\hline Mamoré & Guajará-Mirim (3), Nuar de Yata (1) & 4 \\
Abunã & Extrema (1), Nova Califórnia (2) & 3 \\
Madeira & Porto Velho (131), Distrito de Abunã (1) & 132 \\
Jamari & $\begin{array}{l}\text { Ariquemes (3), Cacaulândia (3), Candeias do Jamari (9), Itapuã do Oeste } \\
\text { (3), Monte Negro (1) }\end{array}$ & 19 \\
Machado & $\begin{array}{l}\text { Jaru (1), Ji-Paraná (19), Machadinho D’Oeste (2), Mirante da Serra } \\
\text { (1), Distrito de Nova Londrina (1), Nova União (1), Ouro Preto do }\end{array}$ & 67 \\
& $\begin{array}{l}\text { Oeste (7), Pimenta Bueno (2), Santa Luzia D’Oeste (3), Tarilândia (0), } \\
\text { Teixeirópolis (1), Vale do Paraíso (1), Vilhena (28) }\end{array}$ & \\
\hline
\end{tabular}

Fonte: Adaptada de Rondônia (1998)

TABELA 2 - Distribuição de pontos de amostragem com determinações químicas.

\begin{tabular}{llc}
\hline \multicolumn{1}{c}{ Bacia } & \multicolumn{1}{c}{ Localização dos pontos de amostragem e número de amostras } & $\begin{array}{c}\text { Total de amostras } \\
\text { em cada bacia }\end{array}$ \\
\hline Mamoré & Guajará-Mirim (3), Nuar de Yata (1) & 4 \\
Abunã & Extrema (1), Nova Califórnia (2) & 3 \\
Madeira & Porto Velho (124), Distrito de Abunã (1) & 125 \\
Jamari & Ariquemes (3), Cacaulândia (3), Candeias do Jamari (9), Itapuã do & 19 \\
& Oeste (3), Monte Negro (1), \\
Machado & $\begin{array}{l}\text { Ji-Paraná (16), Machadinho D'Oeste (2), Mirante da Serra (1), } \\
\text { Distrito de Nova Londrina (1), Nova União (1), Ouro Preto do Oeste } \\
\text { (7), Pimenta Bueno (1), Santa Luzia D’Oeste (1), Tarilândia (1), }\end{array}$ & 56 \\
& Teixeirópolis (1), Vale do Paraíso (1), Vilhena (23)
\end{tabular}

Fonte: Adaptada de Rondônia (1998) 
TABELA 3 - Distribuição de pontos de amostragem com exames bacteriológicos.

\begin{tabular}{llc}
\hline \multicolumn{1}{c}{ Bacia } & \multicolumn{1}{c}{ Localização dos pontos de amostragem e número de amostras } & $\begin{array}{c}\text { Total de amostras em } \\
\text { cada bacia }\end{array}$ \\
\hline Mamoré & Guajará-Mirim (3), Nuar de Yata (1) & 4 \\
Abunã & Extrema (0), Nova Califórnia (2) & 2 \\
Madeira & Porto Velho (235), Distrito de Abunã (1) & 236 \\
Jamari & $\begin{array}{l}\text { Ariquemes (4), Cacaulândia (3), Candeias do Jamari (13), Itapuã do Oeste } \\
\text { (6), Monte Negro (1) }\end{array}$ & 27 \\
Machado & $\begin{array}{l}\text { Jí-Paraná (22), Machadinho D’Oeste (2), Mirante da Serra (1), Distrito } \\
\text { de Nova Londrina (1), Nova União (1), Ouro Preto do Oeste (8), Pimenta }\end{array}$ & 84 \\
& $\begin{array}{l}\text { Bueno (5), Presidente Médici (3), Santa Luzia D’Oeste (3), Tarilândia (1), } \\
\text { Teixeirópolis (1), Vale do Paraíso (1), Vilhena (35) }\end{array}$ & \\
\hline
\end{tabular}

Fonte: Adaptada de Rondônia (1998)

A tabela 4 mostra a distribuição dos valores médios da cor (mg Pt/L), pH e turbidez (UT) obtidos nas bacias estudadas.

TABELA 4 - Valores médios de propriedades físicas.

\begin{tabular}{lccc}
\hline Bacia & $\begin{array}{c}\text { Cor } \\
(m g \text { Pt/l) }\end{array}$ & $p H$ & $\begin{array}{c}\text { Turbidez } \\
(U T)\end{array}$ \\
\hline Mamoré & 4,375 & 4,758 & 4,000 \\
Abunã & 0,833 & 5,433 & 9,000 \\
Madeira & 15,077 & 5,609 & 10,296 \\
Jamari & 6,579 & 5,213 & 5,992 \\
Machado & 6,667 & 6,011 & 2,265 \\
Rondônia & 11,641 & 6,099 & 7,794 \\
\hline
\end{tabular}

Fonte: Modificada de Rondônia (1998)

No período de estudo, mais de $48 \%$ das amostras apresentaram cor igual a $5 \mathrm{ppm}$ de Pt e $10 \%$ valores $>5 \mathrm{ppm}$ de $\mathrm{Pt}$. O maior valor de cor foi registrado em Porto Velho, na bacia do Madeira (500 mg/L de Pt), ultrapassando os limites de potabilidade fixados em até $15 \mathrm{mg} / \mathrm{L}$ de Pt; é o único caso acima do valor médio registrado no Estado de Rondônia (Tabela 4) (BRASIL 2004).

As águas de poços com valores de cor maior que $15 \mathrm{mg} / \mathrm{L}$ devem resultar da existência de substâncias dissolvidas em solução (orgânicas ou inorgânicas). Essas substâncias podem ser originadas, em muitos casos, pela dissolução do $\mathrm{Fe}^{+}$ou de seus complexos metálicos, o que lhes conferem uma coloração característica de águas que percolam solos lateríticos.

$\mathrm{O}$ pH das amostras oscila entre 3,00, em Vilhena e 9,12, em Nova União, ambas situadas na bacia do Machado, sendo que a maioria das águas apresenta $\mathrm{pH}$ entre 5,1 e 5,5 (Tabela 4). Considerando-se os valores médios das bacias estudadas (Tabela 4), apenas o da bacia do rio Machado mantém-se na faixa de 6,0 a 9,5, a recomendada para consumo humano (BRASIL 2004).

No estudo de contaminação do lençol freático na cidade de Ji-Paraná (SILVA 2008), constatou-se que, em todos os pontos e em todas as 12 profundidades amostradas, o $\Delta \mathrm{pH}$ (diferença entre o $\mathrm{pH}$ em $\mathrm{KCl}$ e o $\mathrm{pH}$ em $\mathrm{H}_{2} \mathrm{O}$ ) foi negativo, exceto em duas camadas; tal resultado indicou que o íon nitrato, por ser também de carga negativa, não estava sendo adsorvido nessas camadas de solo, facilitando sua permanência em solução na água infiltrada. $\mathrm{Na}$ análise físico-química da água para abastecimento público da cidade de Porto Velho, SOUZA (2008) confirmou que a maioria dos valores de $\mathrm{pH}$ é menor do que 6,0, abaixo dos valores recomendados (BRASIL 2004).

Os menores valores de $\mathrm{pH}$, associados aos solos ácidos da região, devem-se às elevadas concentrações de $\mathrm{CO}_{2}$ dissolvido na água, resultantes dos processos de decomposição da matéria orgânica que libera gás carbônico.

Todos os valores médios de $\mathrm{pH}$ das bacias estudadas situam-se abaixo do valor médio encontrado para o Estado de Rondônia (Tabela 4) e se assemelham aos valores médios obtidos por MORAIS (1998) nas bacias hidrográficas dos rios Madeira (13 amostras e valor médio de pH 5,46), Jamari (2 
amostras e valor médio de pH 6,83) e Machado (12 amostras e valor médio de $\mathrm{pH} 5,13$ ).

Os resultados de turbidez de poços das bacias dos rios Mamoré e Machado apresentam valores inferiores a 5 UT, aceitáveis para consumo humano, pois os limites recomendados são de, no máximo, 5 UT (BRASIL 2004). Os valores médios de turbidez das bacias do Abunã e do Madeira ficaram acima do valor médio do Estado de Rondônia, enquanto os das bacias do Mamoré e Machado, abaixo desse valor (Tabela 4).

A aplicação do teste de normalidade Kolmogorov-Smirnov, com a modificação de Lilliefors (LILLIEFORS 1967), mostrou que somente as variáveis “cor” na bacia Mamoré $(\mathrm{p}<0,1)$, $\mathrm{pH}$ nas bacias Machado $(p<1,0)$, Madeira $(p<0,1)$ e Mamoré $(\mathrm{p}<1,0)$ e turbidez na bacia do Jamari $(0,15)$ tiveram distribuição normal com 5\% de significância.

Com relação aos parâmetros bacteriológicos, em função da complexidade e do custo, foram analisados somente organismos indicadores da ocorrência de contaminação fecal. Esses organismos, quando presentes na água, evidenciam o risco da presença de organismos patogênicos. Os coliformes fecais são indicadores específicos da presença potencial de organismos patogênicos de origem fecal na água.
A presença de coliformes totais (CT) nas águas pode estar associada às características do terreno, uma vez que a textura do solo, a espessura e a permeabilidade da zona não saturada influem na capacidade de purificação do meio.

Observou-se nos poços amostrados a presença de coliformes totais, com teores que variam de 1 a $2,4 \times 10^{3} \mathrm{NMP} / 100 \mathrm{ml}$, sendo que $22 \%$ deles apresentaram valores maiores ou iguais a 2,4 $\times 10^{3}$ $\mathrm{NMP} / 100 \mathrm{ml}$. Em geral, as águas são impróprias para consumo humano, precisando de fervura ou cloração.

O valor médio de contagem padrão de bactérias em Rondônia (324,96 colônias/ml) situa-se abaixo dos valores médios de todas as bacias estudadas (Tabela 5). Quanto ao número mais provável de coliformes totais, a bacia do rio Madeira foi a única com valor médio (488,73 NMP/100ml) inferior ao de Rondônia (502,43 NMP/100ml). O número mais provável de coliformes fecais, identificado pelo método membrana filtrante, apresentou maior valor médio na bacia do rio Madeira (204,73 $\mathrm{NMP} / 100 \mathrm{ml}$ ). Com relação ao número mais provável de coliformes fecais, na bacia do Mamoré, foi encontrado o maior valor médio $(70,30$ $\mathrm{NMP} / 100 \mathrm{ml}$ ) da área estudada.

TABELA 5 - Parâmetros médios bacteriológicos nas bacias estudadas.

\begin{tabular}{crrrr}
\hline Bacia & $C P B$ & $C T$ & $C F$ & $C M F$ \\
\hline Mamoré & 500,50 & 608,23 & & 70,30 \\
Abunã & 501,00 & 855,00 & 35,00 \\
Madeira & 313,51 & 488,73 & & 63,20 \\
Jamari & 374,29 & 631,467 & 204,73 & 9,38 \\
Machado & 342,53 & 524,59 & 1,43 & 44,90 \\
Rondônia & 324,96 & 502,43 & 124,75 & 54,33 \\
\hline
\end{tabular}

Fonte: Adaptada de Rondônia (1998)

A tabela 5 contém os valores médios identificados de CPB (Contagem Padrão de Bactérias - Colônias/100ml), CT (Número mais provável de Coliformes Totais - NMP/100ml), CF (Número mais provável de Coliformes Fecais - NMP/100ml) e CMF (Número mais provável de Colônias - Método Membrana Filtrante - NCMF/100ml) nas bacias hidrográficas estudadas.

Pelo teste de normalidade Kolmogorov-Smirnov modificado por LILLIEFORS (1967), foi possível identificar que somente as variáveis $\mathrm{CPB}$ (Contagem Padrão de Bactérias) na bacia do Mamoré $(\mathrm{p}<0,2)$ e CMF (Colônias Membrana Filtrante) na bacia do Mamoré $(\mathrm{p}<0,1)$ tiveram distribuição normal com $5 \%$ de significância.

A tabela 6 mostra uma descrição estatística simples das variáveis $\mathrm{V} 1=$ Cloreto $(\mathrm{mg} / \mathrm{L} \mathrm{Cl}), \mathrm{V} 2$ $=$ Ferro total $(\mathrm{mg} / \mathrm{L} \mathrm{Fe}), \mathrm{V} 3=$ Sulfato $\left(\mathrm{mg} / \mathrm{L} \mathrm{SO}_{4}\right)$, $\mathrm{V} 4=$ Oxigênio consumido $\left(\mathrm{mg} / \mathrm{L} \mathrm{O}_{2}\right)$, V5 = Dureza total $\left(\mathrm{mg} / \mathrm{L} \mathrm{CaCO}_{3}\right), \mathrm{V} 6=$ Dureza em cálcio $\left(\mathrm{mg} / \mathrm{L} \mathrm{CaCO}_{3}\right), \mathrm{V} 7$ = Dureza em magnésio $(\mathrm{mg} / \mathrm{L}$ $\left.\mathrm{CaCO}_{3}\right)$, V8 = Sólidos totais $(\mathrm{mg} / \mathrm{L}), \mathrm{V} 9=$ Nitrogênio nitrito $(\mathrm{mg} / \mathrm{L} \mathrm{N}), \mathrm{V} 10=$ Nitrogênio nitrato $(\mathrm{mg} / \mathrm{L} \mathrm{N}), \mathrm{V} 11=$ Gás carbônico livre $\left(\mathrm{mg} / \mathrm{L} \mathrm{CO}_{2}\right)$ e V12 = Alcalinidade $\mathrm{HCO}_{3}\left(\mathrm{mg} / \mathrm{L} \mathrm{CaCO}_{3}\right)$ nas bacias estudadas. 


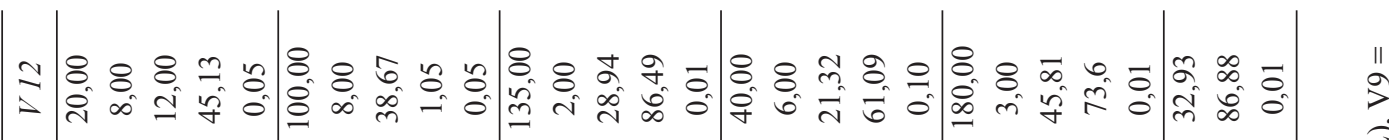

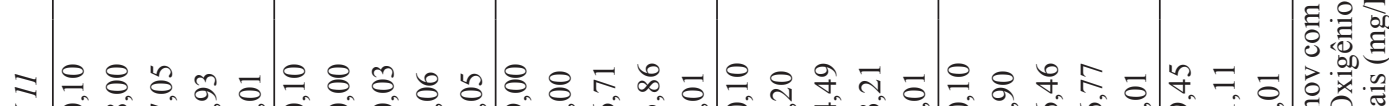

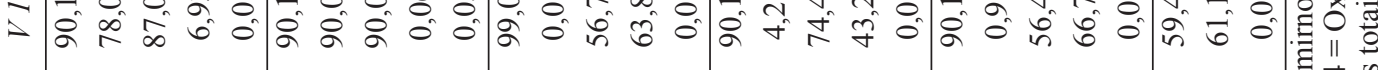

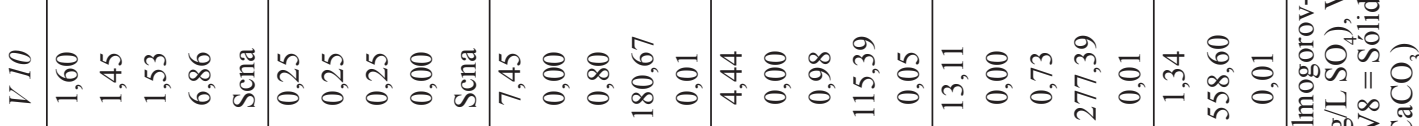

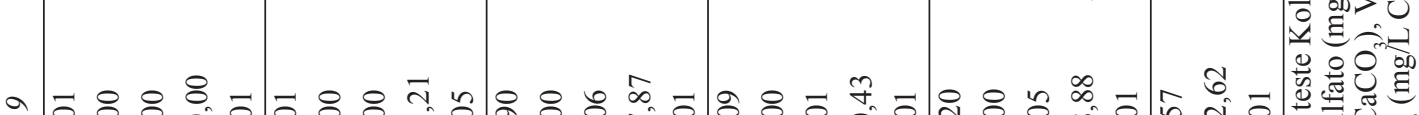
a

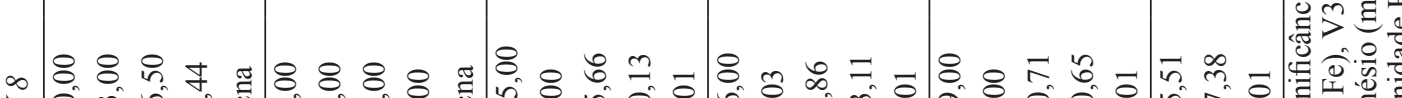
$\checkmark$ 茯

N

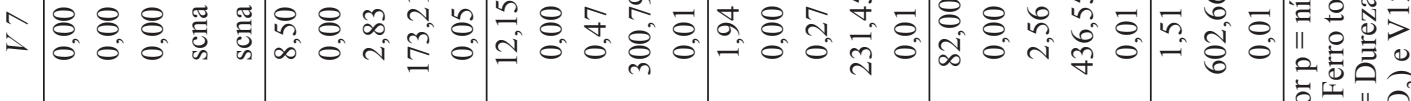

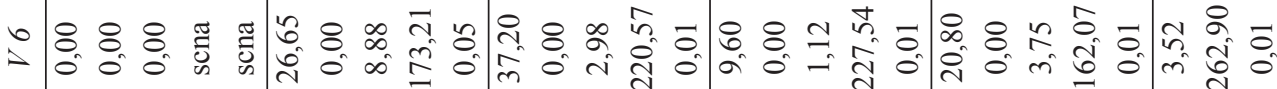

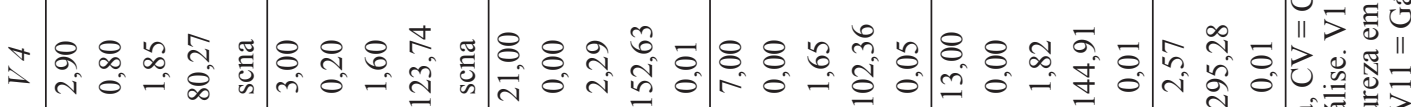

惫 (n)

焉 $\stackrel{8}{8}$ $\Xi x \geq \frac{\bar{c}}{\frac{\pi}{a}}$ $x$ 
A medida do oxigênio consumido permitiu avaliar a disponibilidade de oxigênio para oxidar a matéria orgânica dissolvida ou em solução, considerando-se que o material redutor existente na água fosse, predominantemente, matéria orgânica.

Nas amostras analisadas, os valores de oxigênio consumido oscilaram entre $0 \mathrm{mg} / \mathrm{L}$ de $\mathrm{O}_{2}(\mathrm{em}$ Itapuã do Oeste, na bacia do Jamari e, nos municípios de Ji-Paraná, Machadinho D’Oeste, Pimenta Bueno e Vilhena, na bacia do Machado) e $21 \mathrm{mg} / \mathrm{L}$ de $\mathrm{O}_{2}$ em Porto Velho, na bacia do Madeira. Os maiores valores evidenciaram maior quantidade de matéria orgânica. $\mathrm{O}$ valor médio de oxigênio consumido encontrado para o Estado de Rondônia foi de $2,57 \mathrm{mg} / \mathrm{L}$ de $\mathrm{O}_{2}$, maior do que os valores médios de todas as bacias estudadas (Tabela 6).

Os sólidos totais dissolvidos apresentaram valores mais elevados em Ji-Paraná, na bacia do Machado, e, em Porto Velho, na bacia do Madeira. Os valores mais baixos estão associados a terrenos cristalinos. Os valores mais frequentes ficaram compreendidos entre 101 e $250 \mathrm{mg} / \mathrm{L}$, enquanto o mais elevado (1.215 mg/L) foi encontrado na bacia do Madeira.

Os valores de alcalinidade $\mathrm{HCO}_{3}$ expressam a contribuição dos íons bicarbonato em solução existente nessas águas. A alcalinidade da água reflete sua capacidade de neutralizar ácidos. Nas amostras analisadas, os valores oscilam entre 0 (Pimenta Bueno) e $180 \mathrm{mg} / \mathrm{L}$ de $\mathrm{CaCO}_{3}$ (Machadinho D'Oeste), na bacia do Machado.

Nas águas analisadas, foram encontrados valores de dureza total que variam entre 0 e $100 \mathrm{mg} / \mathrm{L}$ de $\mathrm{CaCO}_{3}$. Os valores de dureza em $\mathrm{Ca}^{2+}$ variam entre 0 e 37,2 mg/L de $\mathrm{CaCO}_{3}$ e os valores de dureza em $\mathrm{Mg}^{2+}$ oscilam entre 0 e $82 \mathrm{mg} / \mathrm{L}$ de $\mathrm{CaCO}_{3}$.

A dureza da água é causada pela presença de cátions metálicos divalentes, principalmente $\mathrm{Ca}^{2+}$ e $\mathrm{Mg}^{2+}$. As águas subterrâneas da área estudada são consideradas brandas (dureza até $60 \mathrm{mg} / \mathrm{L}$ de $\mathrm{CaCO}_{3}$ ) ou moderadamente duras (61 a $120 \mathrm{mg} / \mathrm{L}$ de $\mathrm{CaCO}_{3}$ ). $\mathrm{Na}$ análise físico-química da água para abastecimento público em Porto Velho, SOUZA (2008) registrou teores de dureza total que estavam em conformidade com os valores máximos permitidos de potabilidade (BRASIL 2004).

Considerando o grau de dispersão proposto por GOMES (1990), indicado pelo coeficiente de variação $(\mathrm{CV})$, foi possível identificar que o nitrogênio nitrato e o gás carbônico livre, na bacia do Mamoré, e os teores de cloreto, sólidos totais, nitrogênio nitrato, gás carbônico livre e alcalinidade $\mathrm{HCO}_{3}$, na bacia do Abunã, apresentam baixa dis- persão (Tabela 6). Nos demais casos a dispersão foi muito alta.

Nesta pesquisa, o teor médio de nitrato na bacia hidrográfica do Madeira foi de 1,53 mg/L (Tabela 6). MELO JUNIOR et al. (2006) identificaram que $80 \%$ das amostras estudadas em uma zona urbana de Porto Velho apresentaram teores de nitrato acima de 3,0 mg/L. No trabalho de LIMA (2008), realizado com amostras de 90 poços utilizados pela população da zona sul do perímetro urbano da cidade Porto Velho, localizada na bacia hidrográfica do rio Madeira, 21 poços apresentaram teores de nitrato superior ao valor máximo permitido que é de 10 mg/L (BRASIL 2004).

Após a aplicação do teste de normalidade Kolmogorov-Smirnov modificado por LILLIEFORS (1967) foi possível identificar que somente a variável cloreto na bacia Mamoré $(\mathrm{p}<0,15)$, sulfato na bacia Mamoré $(\mathrm{p}<0,20)$ e alcalinidade $\mathrm{HCO}_{3}$ na bacia do Jamari $(\mathrm{p}<0,10)$ tiveram distribuição normal com $5 \%$ de significância.

Considerando a dispersão dos dados das análises químicas das bacias hidrográficas dos rios Madeira e Machado, identificaram-se semelhanças entre os dados estatísticos obtidos neste trabalho e os resultados de MORAIS (1998) nos atributos de sólidos totais e alcalinidade, na bacia do rio Madeira (13 amostras) e de cloreto, dureza em cálcio e alcalinidade, na bacia do rio Machado (12 amostras). No caso da bacia do rio Jamari (2 amostras), os valores de dispersão encontrados por MORAIS (1998) ficaram abaixo dos valores desta pesquisa, considerando os atributos cloreto, ferro total, sulfato, dureza total, dureza em cálcio, dureza em magnésio, sólidos totais e alcalinidade (Tabela 7).

O processo de contaminação da água dos poços das bacias hidrográficas é decorrente diretamente da forma de adensamento populacional ocorrida. No caso particular da bacia do rio Madeira, com o maior contingente populacional do estado, o valor máximo do teor de nitrato em 1997 (RONDÔNIA 1998) foi de 7,45 mg/L (Tabela 6). De acordo com resultados de pesquisas mais recentes na mesma bacia, os teores de nitrato têm aumentado (Tabela 8).

\subsection{Aptidão das águas subterrâneas para consumo humano}

A qualidade das águas subterrâneas, associada à sua adequabilidade para o consumo humano, foi analisada sob os aspectos mais genéricos com base nas características físicas e químicas, mostrando as principais restrições quanto ao uso. Uti- 
TABELA 7 - Distribuição dos dados de propriedades químicas nas bacias dos rios Madeira, Jamari e Machado.

\begin{tabular}{|c|c|c|c|c|c|c|c|c|c|}
\hline Bacia & Medida & Cloreto & $\begin{array}{r}\text { Ferro } \\
\text { Total } \\
\end{array}$ & Sulfato & $\begin{array}{r}\text { Dureza } \\
\text { Total }\end{array}$ & $\begin{array}{r}\text { Dureza em } \\
\text { Cálcio }\end{array}$ & $\begin{array}{c}\text { Dureza em } \\
\text { Magnésio }\end{array}$ & $\begin{array}{r}\text { Sólidos } \\
\text { Totais } \\
\end{array}$ & Alcalinidade \\
\hline \multirow{4}{*}{ Madeira } & Máx & 16,83 & 0,52 & 274,41 & 280,00 & 101,00 & 13,16 & 588,00 & 217,50 \\
\hline & Mín & 1,02 & 0,02 & 0,18 & 2,40 & 0,16 & 0,02 & 18,00 & 0,83 \\
\hline & X & 5,00 & 0,12 & 84,71 & 82,75 & 25,99 & 2,33 & 132,92 & 90,86 \\
\hline & $\mathrm{CV}$ & 101,15 & 119,57 & 88,46 & 101,93 & 147,24 & 168,58 & 138,60 & 64,81 \\
\hline \multirow{4}{*}{ Jamari } & Máx & 15,30 & 0,11 & 101,00 & 72,60 & 12,80 & 6,82 & 158,00 & 65,00 \\
\hline & Mín & 4,59 & 0,06 & 101,00 & 63,00 & 8,96 & 6,44 & 144,00 & 62,50 \\
\hline & X & 9,95 & 0,08 & 101,00 & 67,80 & 10,88 & 6,63 & 151,00 & 63,75 \\
\hline & $\mathrm{CV}$ & 76,15 & 43,65 & 0,00 & 10,01 & 24,96 & 4,05 & 6,56 & 2,77 \\
\hline \multirow{4}{*}{ Machado } & Máx & 101,00 & 0,87 & 101,00 & 103,20 & 15,31 & 11,36 & 200,00 & 115,00 \\
\hline & Mín & 0,75 & 0,00 & 0,18 & 2,20 & 0,26 & 0,02 & 18,00 & 0,89 \\
\hline & X & 12,79 & 0,11 & 42,38 & 34,33 & 3,90 & 2,69 & 82,17 & 46,52 \\
\hline & $\mathrm{CV}$ & 219,89 & 213,65 & 122,13 & 104,27 & 113,66 & 122,47 & 65,96 & 89,72 \\
\hline
\end{tabular}

Max = valor máximo, Min = valor mínimo, $\mathrm{X}=$ média aritmética, $\mathrm{CV}=$ coeficiente de variação.

Fonte: Modificada de Morais (1998)

lizou-se como referência o padrão de potabilidade constante na Portaria ${ }^{\circ}$. 518/2004 do Ministério da Saúde (BRASIL 2004). A tabela 9 mostra os limites máximos permissíveis de alguns parâmetros, adotando-se o mesmo padrão utilizado para as águas subterrâneas do Estado de Rondônia.
As principais restrições referem-se aos valores muito baixos de $\mathrm{pH}$ e aos teores excessivos de nitrato e ferro total. De forma subordinada, encontram-se como fatores restritivos, concentrações acima dos limites de cor, turbidez e cloretos em algumas amostras.

TABELA 8 - Valores de nitrato $(\mathrm{mg} / \mathrm{L})$ em amostras de água de poços na bacia hidrográfica do rio Madeira de 2002 até 2007.

\begin{tabular}{lcccccc}
\hline \multicolumn{1}{c}{ Autor } & \multicolumn{5}{c}{ Ano } \\
& 2002 & 2003 & 2004 & 2005 & 2006 & 2007 \\
\hline SOUZA (2008) & 0,007 & $<0,1$ & - & 0,4 & 1,8 & 1,4 \\
COSTA (2008) & & & & & & 13,07 \\
LIMA (2008) & & & & & & 114,72 \\
\hline
\end{tabular}

TABELA 9 - Limites para potabilidade das águas subterrâneas.

\begin{tabular}{lcl}
\hline \multicolumn{1}{c}{ Parâmetros } & VMP & \multicolumn{1}{c}{ Observações (Estado de Rondônia) } \\
\hline Cor & $15 \mathrm{mg} \mathrm{Pt} / \mathrm{L}$ & Valores excessivos pouco frequentes \\
Turbidez & $5 \mathrm{UT}$ & Valores elevados em algumas amostras \\
$\mathrm{pH}$ & $6,0 \mathrm{a} \mathrm{9,5}$ & $\begin{array}{l}\text { Em geral valores muito baixos são frequentes. Com } \\
\text { restrições locais }\end{array}$ \\
Sólidos totais dissolvidos & $1000 \mathrm{mg} / \mathrm{L}$ & Sem restrições \\
Dureza total & $500 \mathrm{mg} / \mathrm{L} \mathrm{de} \mathrm{CaCO3}$ & Sem restrições \\
Cloretos & $250 \mathrm{mg} / \mathrm{L}$ & Valores elevados em algumas amostras \\
Sulfatos & $250 \mathrm{mg} / \mathrm{L}$ & Sem restrições \\
Nitratos & $10 \mathrm{mg} / \mathrm{L}$ & Restrições locais. Teores excessivos são comuns em \\
& & algumas áreas \\
Ferro Total & $0,3 \mathrm{mg} / \mathrm{L}$ & Valores elevados em algumas amostras \\
\hline VMP = Valor máximo permitido, Portaria n ${ }^{\circ} .518 / 2004$ Ministério da Saúde. \\
Fonte: Adaptada de Rondônia (1998)
\end{tabular}


3.2 Aptidão das águas subterrâneas para a dessedentação de animais

Os critérios para estabelecer a qualidade das águas para o consumo de animais não são bem definidos, tal como aqueles utilizados para o consumo humano. A complexidade para estabelecer parâmetros de água para consumo animal está associada a variáveis que dependem não só da espécie, mas também da variedade dos animais, bem como do tipo de alimentação e do clima. Nas tabelas 10 e 11 , constam alguns valores de referências de STD (sólidos totais dissolvidos) para consumo animal.

TABELA 10 - Limites de STD nas águas subterrâneas para uso em pecuária.

\begin{tabular}{ll}
\hline STD $(\mathrm{mg} / \mathrm{L})$ & Qualidade \\
\hline$\leq 2.500$ & Boa \\
De 2.500 a 3.500 & Satisfatória \\
De 3.500 a 4.500 & Ruim \\
$>4.500$ & Insatisfatória \\
\hline
\end{tabular}

Fonte: Logan apud Santos (1997)

TABELA 11 - Limites de STD nas águas subterrâneas para consumo animal.

\begin{tabular}{ll}
\hline$S T D(m g / L)$ & Animal \\
\hline 2.860 & Aves \\
4.220 & Porcos \\
6.435 & Cavalos \\
7.180 & Gado (leite) \\
10.000 & Gado (corte) \\
12.900 & Carneiro \\
\hline
\end{tabular}

Fonte: Mackee \& Wolf apud Santos (1997).
As águas subterrâneas de Rondônia apresentaram valores médios de sólidos dissolvidos inferiores a $250 \mathrm{mg} / \mathrm{L}$. Foram registrados valores anômalos de $1.215 \mathrm{mg} / \mathrm{L}$, em Porto Velho, na bacia do Rio Madeira, e 939 mg/L, em Ji-Paraná, na bacia do rio Machado, que podem ser explicados pela maior concentração populacional nas cidades e pelo crescente processo de industrialização.

\subsection{Aptidão das águas subterrâneas para irrigação}

Tendo em vista a não realização de análises dos valores de sódio e condutividade elétrica das águas amostradas, não foi realizada uma classificação quanto à qualidade das águas subterrâneas para irrigação.

Considerando-se os dados de sólidos dissolvidos totais, cloreto total, ferro dissolvido, nitrato, nitrito e sulfato total; levando-se em conta os limites estabelecidos para as águas de classe 3, na Resolução no. 357/2005 do Conselho Nacional do Meio Ambiente - CONAMA, Ministério do Meio Ambiente (BRASIL 2005b), a tabela 12 mostra os limites de alguns parâmetros de água para irrigação utilizados para analisar as águas subterrâneas do Estado de Rondônia.

Muito embora os valores médios encontrados não tenham ultrapassado os valores máximos permitidos para as variáveis consideradas na tabela 12, com exceção do sulfato total nas 5 bacias hidrográficas, os valores máximos de sólidos dissolvidos totais, cloreto total, ferro total e nitrito das bacias do Madeira e do Machado ficaram acima do valor máximo permitido; vale lembrar, também, a ocorrência de nitrato na bacia do rio Machado.

\section{CONCLUSÕES}

Considerando-se os resultados obtidos e os padrões estabelecidos para cor, potencial hidroge-

TABELA 12 - Limites de parâmetros nas águas subterrâneas para irrigação.

\begin{tabular}{lcc}
\hline \multicolumn{1}{c}{ Parâmetros } & $V M P$ & Valores Médios (Rondônia) \\
\hline Sólidos dissolvidos totais & $500 \mathrm{mg} / \mathrm{L}$ & $115,51 \mathrm{mg} / \mathrm{L}$ \\
Cloreto total & $250 \mathrm{mg} / \mathrm{L} \mathrm{Cl}$ & $29,65 \mathrm{mg} / \mathrm{L} \mathrm{Cl}$ \\
Ferro dissolvido & $5,0 \mathrm{mg} / \mathrm{L} \mathrm{Fe}$ & $2,05 \mathrm{mg} / \mathrm{L} \mathrm{Fe}$ \\
Nitrato & $10,0 \mathrm{mg} / \mathrm{L} \mathrm{N}$ & $1,34 \mathrm{mg} / \mathrm{L} \mathrm{N}$ \\
Nitrito & $1,0 \mathrm{mg} / \mathrm{L} \mathrm{N}$ & $0,57 \mathrm{mg} / \mathrm{L} \mathrm{N}$ \\
Sulfato total & $250 \mathrm{mg} / \mathrm{L} \mathrm{SO}_{4}$ & $2,85 \mathrm{mg} / \mathrm{L} \mathrm{SO}_{4}$ \\
\hline
\end{tabular}

VMP = Valor máximo permitido, Resolução n 357/2005 - CONAMA

Fonte: Adaptada de Rondônia (1998) 
niônico ( $\mathrm{pH})$ e turbidez, constata-se que a maioria das amostras analisadas pode ser considerada de boa qualidade físico-organoléptica.

Considerando os dados de contagem padrão de bactérias e de coliformes totais nas bacias estudadas, a bacia hidrográfica do rio Abunã é a que apresenta maior risco de contaminação fecal.

Salienta-se que, em geral, as águas subterrâneas analisadas apresentam resultados que excedem os padrões bacteriológicos de potabilidade, necessitando de tratamento por cloração ou fervura e prévia filtração para consumo humano.

Alguns dados de parâmetros químicos estão fora dos limites aceitáveis, indicando, pontualmente, qualidade imprópria de água para o consumo humano.

As bacias dos rios Madeira e Machado apresentam, de modo geral, maiores alterações, particularmente nos valores de $\mathrm{pH}$, cloreto e nitrato, caracterizando perda de qualidade dos recursos hídricos subterrâneos, tendo em vista que as mesmas possuem os maiores adensamentos populacionais de Rondônia e não foram adotadas medidas satisfatórias para utilização racional dos referidos recursos.

Os valores máximos de nitrato ilustram de forma significativa o avanço da contaminação na bacia hidrográfica do rio Madeira, evoluindo de 7,42 mg/L, no ano de 1997 (RONDÔNIA 1998), para $114,72 \mathrm{mg} / \mathrm{L}$ (LIMA 2008).

A dispersão de teores das variáveis foi calculada pelo coeficiente de variação, com base em valores sugeridos para experimentos de campo com culturas agrícolas; consequentemente, não deve ser aplicado a recursos hídricos onde as condições experimentais diferem significativamente de outros experimentos de campo. Dessa forma, fica evidenciada a necessidade de se estudar a distribuição dos valores de coeficiente de variação em pesquisas com recursos hídricos.

Os parâmetros utilizados para se avaliar as características físico-químicas e bacteriológicas das águas subterrâneas, além de servirem de referência a estudos mais recentes, podem ser úteis para se estabelecer um índice da qualidade das águas subterrâneas de Rondônia.

\section{AGRADECIMENTOS}

Os autores agradecem à Secretaria de Estado de Planejamento e Coordenação Geral (SEPLAN/ RO), pela autorização para utilização dos dados e informações disponíveis no Relatório de Hidroge- ologia do $2^{\circ}$ ZSEE/RO (RONDÔNIA 1998) e aos revisores, pelas sugestões que aprimoraram este trabalho, que faz parte da tese "Gestão Integrada das Águas em Rondônia”, de Catia Eliza Zuffo no PPGG/UFPA.

\section{REFERÊNCIAS BIBLIOGRÁFICAS}

AMARAL, G. 1984. Províncias Tapajós e Rio Branco. In: F.F.M. de Ameida \& Y. Hasui (ed.) O Pré-Cambriano do Brasil. São Paulo, Edgard Blucher, p.6-35.

BAHIA, M.A.S. 1997. Caracterização biogeoquímica de águas subterrâneas da zona urbana de Porto Velho. Universidade Federal do Pará, Belém, Dissertação de Mestrado, 129p.

BARBOSA, C.M.S.; MATTOS, A. 2006. Gestão participativa das águas subterrâneas. In: CONGRESSO BRASILEIRO DE ÁGUAS SUBTERRÂNEAS, 14, Curitiba, Anais, CD-Rom, p. 1-6.

BRASIL. 1997. Ministério do Meio Ambiente. Secretaria de Recursos Hídricos. Associação Brasileira de Educação Agrícola Superior. Lei $n^{\circ} .9 .433$ de 8 de janeiro de 1997 - Política Nacional de Recursos Hídricos. Brasília, MMA. $17 \mathrm{p}$.

BRASIL. 2004. Ministério da Saúde. Secretaria de Vigilância em Saúde. Coordenação-Geral de Vigilância em Saúde Ambiental. Portaria MS no. 518/2004. Brasília. Disponível em: $<$ http://portal.saude.gov.br/portal/arquivos/ pdf/portaria_518_2004.pdf $>$. Acesso em: Ago. 2009. 34p.

BRASIL. 2005a. Ministério do Meio Ambiente. II Conferência nacional do meio ambiente: Política ambiental integrada e uso sustentável dos recursos naturais. Texto-base. Brasília, MMA. 15p.

BRASIL. 2005b. Ministério do Meio Ambiente. Conselho Nacional do Meio Ambiente - CONAMA. Resolução CONAMA no. 357 de 17 de março de 2005. Brasília. Disponível em: <http://www. mma.gov.br/port/conama/res/res05/res35705. pdf $>$. Acesso em: Ago. 2009. 23p.

CAMPOS, J.C.V. 2004. Contaminação das águas subterrâneas na cidade de Mirante da Ser- 
ra (RO). In: CONGRESSO BRASILEIRO DE ÁGUAS SUBTERRÂNEAS, 13, Cuiabá, Anais. Disponível em: <http://www. cprm.gov.br/publique/media/contami_serra_ ro.pdf>. Acesso em: Ago. 2009. 11p.

CAMPOS, J.C.V. \& DREWS, M.G.P. 1999. Avaliação do potencial hidrogeológico da área urbana do distrito de Extrema município de Porto Velho RO. Relatório Técnico - convênio CPRM/FNS. Porto Velho: CPRM, 23p.

CAMPOS, J.C.V.; DREWS, M.G.P.; SCANDOLARA, J.E. 1999a. Avaliação do potencial hidrogeológico da área urbana do distrito de Nova Califórnia município de Porto Velho RO. Relatório Técnico - convênio CPRM/ FNS. Porto Velho: CPRM, 19p.

CAMPOS, J.C.V.; DREWS, M.G.P.; SCANDOLARA, J.E. 1999b. Avaliação do potencial hidrogeológico da área urbana do município de Buritis Estado de Rondônia. Relatório Técnico - convênio CPRM/FNS. Porto Velho: CPRM, 26p.

CAMPOS, J.C.V.; DREWS, M.G.P.; SCANDOLARA, J.E. 1999c. Avaliação do potencial hidrogeológico da área urbana do município de Campo Novo de Rondônia RO. Relatório Técnico - convênio CPRM/FNS. Porto Velho: CPRM, 28p.

CAMPOS, J.C.V.; REIS, M.R.A. 2002. Subprograma de apoio ao desenvolvimento dos municípios da Amazônia - ADEMA. Município de Ariquemes, Estado de Rondônia. Recursos hídricos. Série ADEMA, vol. 3. Porto Velho: CPRM, 30p.

CAMPOS, J.C.V., SILVA F ${ }^{\circ}$, E.P. e OLIVEIRA, I.R. 2004. Contaminação do Aquífero Jaciparaná na Cidade de Porto Velho-RO. Disponível em: $<$ http://www.cprm.gov.br/publique/cgi/cgilua.exe/sys/start.htm? infoid $=292 \&$ sid $=36>$. Acesso em: Set. 2009, 10p.

COSTA, A.F. 2008. Emprego do método da eletroresistividade na caracterização da área da lixeira de Porto Velho - RO assentada em meio fraturado. Instituto de Geociências e Ciências Exatas, Universidade Estadual Paulista, Rio Claro, Tese de Doutorado, 128p.

FONSECA, J.S. 1985. Estatística aplicada. São Paulo, Editora Atlas, 320p.
FOSTER, S. 1993. Poluição das águas subterrâneas: um documento executivo da situação da América Latina e Caribe com relação ao abastecimento de água potável. Tradução de Ricardo Hirata. São Paulo: Instituto Geológico (Boletim, 10), 55p.

GOMES, F.P. 1990. Curso de estatística experimental. 12. ed. São Paulo: Nobel, 467p.

LILLIEFORS, H.W. 1967. On the KolmogorovSmirnov test for normality with mean and variance unknown. Journal of the American Statistical Association, 62(318): 399-402.

LIMA, M.L.A. 2008. Águas subterrâneas potencialmente impactadas por nitrato $\left(\mathrm{NO}_{3}\right)$ na área urbana da cidade de Porto Velho: um estudo da geografia da saúde. Fundação Universidade Federal de Rondônia, Porto Velho, Dissertação de Mestrado, 76p.

LIMA, M.L.A.; CHAVES, C.A.P.; MELO JUNIOR, H.R.; SIMÃO, F.B. 2008. Aplicação de métodos geoestatisticos para mapeamento de área de risco em saúde pública no município de Porto Velho-RO. Vita et Sanitas, 2(2): 130-149.

MELO JUNIOR, H.R. \& COSTI, A.C.Z. 2004. Avaliação da contaminação das águas subterrâneas por hidrocarbonetos provenientes de posto de abastecimento de combustível na Vila Tupi, Porto Velho (RO). Disponível em <http:// www.cprm.gov.br/publique/media/avali_contami.pdf $>$. Acesso em: Set. 2009. 19p.

MELO JUNIOR, H.R. LIMA, M.L.A; SILVA, M.B. MELO, R.F. 2006. Avaliação da qualidade das águas subterrâneas em uma zona urbana da Amazônia brasileira: estudo de caso do bairro Eletronorte, Porto Velho (RO). In: CONGRESSO BRASILEIRO DE ÁGUAS SUBTERRÂNEAS, 14, Curitiba, Anais, CD-Rom, 20p.

MELO JUNIOR, H.R. 2007. Amazônia planeta água - paradoxos sobre a gestão das águas subterrâneas na maior bacia hidrográfica do Planeta: estudos de casos em Porto Velho (RO) e Rio Branco (AC). In: SIMPÓSIO DE GEOLOGIA DA AMAZÔNIA, 10, Porto Ve1ho, Anais, p.503-505.

MORAIS, P.R.C. 1998. Mapa hidrogeológico do Estado de Rondônia: texto explicativo. Porto 
Velho: CPRM - Serviço Geológico do Brasil. Residência de Porto Velho: CPRM, 40p.

REBOUÇAS, A.C. 1997. Água na região Nordeste: Desperdício e escassez. Estudos Avançados, 11(29): 127-154.

REIS, M.R.; MORAIS, P.R.C.; ADAMY, A. 1998. Programa de integração mineral em municípios da Amazônia - Primaz, Pimenta Bueno Estado de Rondônia. Recursos hídricos. Série PRIMAZ, vol. 8. Porto Velho: CPRM, 35p.

RODRIGUES, E.R.D. 2008. Avaliação Espacial da Qualidade da Água Subterrânea na Área Urbana de Porto Velho - Rondônia / Brasil. Fundação Universidade Federal de Rondônia, Porto Velho, Dissertação de Mestrado, 70p.

RONDÔNIA. 1998. Plano Agropecuário e Florestal de Rondônia - PLANAFLORO. Zoneamento Sócio-econômico-ecológico do Estado de Rondônia. Relatório de Hidrogeologia. Rondônia: Planafloro, 264p.

RONDÔNIA, 2002a. Lei Complementar no. 255 de 25 de janeiro de 2002. Porto Velho: SEDAM, 20 p.

RONDÔNIA, 2002b. Decreto $\mathrm{n}^{\circ}$. 10.114, de 20 de setembro de 2002. Porto Velho: SEDAM, 22p.

SANTOS, A.C. 1997. Noções de hidroquímica. In: Hidrologeologia: conceitos e aplicações. Fortaleza: CPRM, LABHID-UFPE. p. 81-108.
SCANDOLARA, J.E.; RIZZOTTO, G.J.; BAHIA, R.B.C.; QUADROS, M.L.E.S.; AMORIM, J.L.; DALL'IGNA, L.G. 1999. Geologia e recursos minerais do Estado de Rondônia: texto explicativo e mapa geológico na escala 1:1 000 000. Programa Levantamento Geológico do Brasil. CPRM - Serviço Geológico do Brasil, Brasília, Brasil.

SEDAM - SECRETARIA DE ESTADO DO DESENVOLVIMENTO AMBIENTAL. 2002. Atlas Geoambiental de Rondônia. SEDAM, Porto Velho, 73p.

SILVA, A.C. 2001. Potabilidade das águas subterrâneas de Ji-Paraná. Estudo de caso: Bairro Nova Brasília. Instituto de Geociências e Ciências Exatas, Universidade Estadual Paulista, Rio Claro, Dissertação de Mestrado, 91p.

SILVA, A.C. 2008. Estudo da contaminação do lençol freático através da integração de técnicas geoquímicas e geofísicas em Ji-Paraná, RO. Instituto de Geociências e Ciências Exatas, Universidade Estadual Paulista, Rio Claro, Tese de Doutorado, 146p.

SOUZA, S.A.S. 2008. Análise físico-química da água para abastecimento público da cidade de Porto Velho. Fundação Universidade Federal de Rondônia, Porto Velho, Monografia de Conclusão de Curso, 48p.

THODE JR., H.C. 2002. Testing for Normality. Marcel Dekker, New York, 463p.

Endereço dos autores:

Catia Eliza Zuffo - Departamento de Geografia, Núcleo de Ciências e Tecnologia da Universidade Federal de Rondônia - UNIR, Caixa Postal 1647, CEP 76801-974, Porto Velho, RO. E-mail: catiazuffo@gmail. com

Francisco de Assis Matos de Abreu - Instituto de Geociências da Universidade Federal do Pará, UFPA, Cidade Universitária Prof. José da Silveira Netto, Caixa Postal 1611, CEP 66075-900, Belém, PA. E-mail: famatos@ufpa.br

Itabaraci Nazareno Cavalcante - Centro de Ciências da Universidade Federal do Ceará - UFC, Campus Universitário do Pici, Departamento de Geologia, Blocos 912/913, CEP 60450-000, Fortaleza, CE. E-mail: ita@fortalnet.com.br

Gerson Flôres Nascimento - Departamento de Engenharia de Alimentos, Campus de Ariquemes, Universidade Federal de Rondônia - UNIR, Av. Tancredo Neves, 3450, Setor Institucional, CEP 76872-862, Ariquemes, RO. E-mail: gersonfn@unir.br 